\title{
LAS PIONERAS. ESCULTORAS ESPAÑOLAS EN LA 2a REPÚBLICA
}

\author{
PIONEERS WOMEN. SPANISH SCULPTRESS IN THE SECOND REPUBLIC
}

Raquel Barrionuevo Pérez

Universidad de Sevilla

\section{Resumen:}

Aquellas pioneras que consolidaron su andadura en la escultura durante la $2^{\mathrm{a}}$ República conforman un nuevo modelo de mujer que se incorpora activamente a los ambientes artísticos. Aunque no pudieron acceder al aprendizaje académico oficial, recibieron lecciones de los escultores más ilustres del momento. Todas estas escultoras tuvieron vínculo familiar con destacados intelectuales $\mathrm{o}$ artistas, permaneciendo a la sombra de sus padres o maridos, en un papel secundario. Sufrieron críticas por adentrarse en la escultura, un campo "no apto" para ellas. Pero una profunda vocación y un talento demostrado les hizo superar los impedimentos y entregarse al modelado de sus obras. Estas mujeres dejaron una herencia, son un referente para la primera generación de escultoras profesionales en nuestro país que surgirá unas décadas más tarde. Revelar sus nombres y rescatar sus obras, nos da la oportunidad de recuperar la memoria de estas mujeres y valorar con perspectiva sus trabajos.

\section{Palabras claves:}

Escultoras, 2ª República, mujeres.

\section{Abstract:}

Those pioneers who consolidated their careers in sculpture in the 2nd Republic constitute a new model of woman who actively incorporates to artistic circles. Although they could not access the official academic learning, they received lessons from the most famous sculptors of the time. All these sculptresses had family ties to prominent intellectuals and artists, standing in the shadow of their fathers or husbands, in a supporting role. They were criticized for working in sculpture, a field "unfit" for them. But a deep commitment and a proven talent made them overcome the impediments and given to the modeling of their works. These women left an inheritance, they are a reference to the first generation of professional sculptresses in our country that will emerge a few decades later. Disclose their names and rescue their works, gives us the opportunity to recover these women's memory and evaluate their works in perspective.

\section{KEY WORD:}

Sculptresses, 2nd Republic, women. 
Aquellas pioneras que consolidaron su andadura en la escultura en la $2^{\underline{a}}$ República, conforman un nuevo modelo de mujer que se enfrenta a los valores establecidos, cuadrando con el perfil de lo moderno, y que se incorpora activamente a los ambientes artísticos. Si bien no pudieron acceder al aprendizaje académico oficial, recibieron lecciones de los escultores más destacados del momento. De clase acomodada y apellido destacado, todas sufrieron los prejuicios de la crítica por adentrarse en un campo "no apto" para ellas, pero una profunda vocación descubierta y un talento demostrado les hizo superar los impedimentos y entregarse al modelado de sus esculturas. Elegirán la figura femenina, el retrato psicológico y los temas costumbristas como argumento de sus obras. Aunque todas tuvieron contacto con los círculos culturales, resultado del vínculo familiar con destacados intelectuales o artistas del momento, no les fue permitido brillar con luz propia, permaneciendo a la sombra de su padre o marido, en un papel secundario. Aun así, estas autoras dejaron una herencia que intervino en el rumbo de nuestra historia. Abrieron un camino de referentes a las mujeres que se incorporaron a la práctica escultórica décadas más tarde y que conformarían la primera generación de escultoras profesionales en nuestro país. Revelar sus nombres y rescatar sus obras, nos da la oportunidad de recuperar su memoria y valorar con perspectiva su trabajo.

\section{Contexto de España y su repercusión en la creación plástica}

La situación del país, a principios del siglo XX, es de atraso en todos los frentes, los niveles de analfabetismo son grandes, existen considerables desigualdades sociales y una burguesía que acapara el poder. Todo esto llevado al ámbito cultural se traduce en un monopolio del mercado artístico por la clase dominante y, por tanto, el impedimento para cualquier signo de innovación, puesto que en general, la burguesía española invertirá en obras tradicionales y académicas. Encontramos una excepción en la burguesía catalana, con mayor formación intelectual estará más preparada para asimilar las innovaciones que se irán produciendo. Aún así, la escultura no contará con el apoyo económico de los coleccionistas que preferirán, por lo general, invertir en pintura, ni con la ayuda del estado español. Éste, al igual que ocurría en el resto de países europeos, se centrará en financiar monumentos públicos, de carácter conmemorativo sobre los que desplegará sus ideologías, controlando su estilo, sin dar opción a nuevas aportaciones.

En los años 20 y 30, mientras Europa vive el receso provocado por la Primera Guerra Mundial (1914-1918), España vivirá el desarrollo del cubismo y del surrealismo. El año 1925, presidido por la celebración de la Exposición de los Iberos en Madrid, marcará el inicio de un periodo de progreso con el florecimiento algunas de las propuestas más interesantes de nuestros artistas de vanguardia. Serán años de constante ebullición sucediéndose las exposiciones, los manifiestos, las agrupaciones efímeras, se crean revistas ${ }^{1}$, galerías, salas de exposiciones y se buscan modos alternativos de difusión de la obra, alejados de lo oficial, como el Salón de los Independientes, que tuvo su primera exposición en 1929. La llegada de la 2ª República presidirá el periodo que podríamos definir como el más fructífero de la vanguardia española. En ese contexto, un nuevo modelo de mujer se va a incorporar a los ambientes profesionales y artísticos. Esta artista, arriesgada y luchadora, cuadrará con el perfil de lo moderno, de lo que se concebía como de vanguardia, ya que supone un enfrentamiento con los valores establecidos y una lucha por la independencia y la libertad. De ahí que el artista varón no podrá negarse a aceptarla como compañera, se le tildaría de no moderno, de no vanguardista, y aunque no la ayuda tampoco se opondrá a ella. Ésta logra superar el rechazo de etapas previas y sentar las bases para su trabajo.

Así mismo se produce una mejora en la situación general de la mujer española gracias a la Constitución Republicana que, llegó a ser una de la más avanzada en leyes como la del divorcio. Curiosamente el primer divorcio de la República, en 1932, fue entre la escultora María Pérez-Péix y el escritor Eugenio d'Ors. En 1931 la mujer obtuvo su derecho al voto y se llevó a cabo la reforma del Código Civil. La mujer casada podía conservar su nacionalidad, tenía personalidad jurídica completa y poseía idéntica autoridad sobre los hijos que el padre. Por otro lado, frente a la legislación del Código Civil de 1889 que aprobaba el papel de dependencia y sumisión de la mujer ${ }^{2}$ y en el que dejaba claro que la esposa no podía tener bienes propios, la reforma del Código Civil, aprueba que la administración matrimonial se lleve conjuntamente por ambos cónyuges. Muchas mujeres, toman conciencia de su nueva situación y sus voces se oyen en mítines, a través de la prensa y de su obra. Su actividad reivindicadora durante aquellos años fue extraordinaria.

\section{Manifestaciones escultóricas}

El panorama escultórico en la península al comenzar el siglo será desolador. La mayoría de los artistas seguirán anclados en viejas recetas y apenas se difunden los avances en escultura que artistas de la vanguardia, como Picasso o Julio González, están alcanzando en París. Las Exposiciones Nacionales ${ }^{3}$ serán en parte culpables del escaso desarrollo, al apoyar durante años un arte caduco, sin apenas relación con lo que sucedía en la plástica internacional. “Los Salones de Exposiciones Nacionales

1 En 1932 se funda la revista más importante del momento Gaceta de Arte, que apoyaría la vanguardia hasta la Guerra Civil. Tras Los Iberos, florece La Gaceta Literaria, en Madrid, Gallo, en Granada, Mediodía, en Sevilla, L'Amic de les Arts, en Sitges y Litoral, en Málaga.

2 En su artículo 57 estipula que "El marido debe proteger a la mujer y ésta obedecer al marido", y el artículo 59 añade que "El marido es el administrador de los bienes de la sociedad conyugal".

3 Se crearon por decreto de Isabel II el 28 Diciembre de 1853, inaugurándose la primera en 1856. 
se llenaban de auténticos monumentos al mal gusto, de faunos, ninfas, Penélopes y Viriatos. Veníamos bebiendo de las fuentes de la imaginería, de un neoclasicismo ramplón y de un romanticismo prácticamente inexistente". (Alix 1985: 29) "Fueron la tapadera angélica que ocultaba todas las quiebras del arte español y cerraba el paso a todo posible arrebato creativo dispuesto a saltar, sobre el corpus de nuestro pobre arte" (De Castro 1987:5).

Muchos escultores que apostaron por la innovación tuvieron que marchar a París, o en el peor de los casos, dejar su pueblo o ciudad e ir a Barcelona o Madrid, principales centros de desarrollo artístico en la península. Si Madrid, recoge las propuestas más tradicionales apoyándose en la vertiente de Bourdelle, Barcelona, será la que desarrolle el Modernismo y la escultura mediterránea heredera de Maillol. Las escultoras que quieran viajar tendrán el problema más acentuado por los condicionantes sociales. Un pasaporte seguro será estar vinculada familiarmente con un artista, siendo común encontrar escultoras ${ }^{4}$ casadas con uno de ellos.

A pesar del contexto expuesto, en los años 20 y 30, comenzará una nueva etapa para la escultura figurativa, alejada de los cauces puramente académicos. Ésta estará encabezada por José Clará como símbolo del mediterraneísmo catalán y por Victorio Macho y José Capuz como figuras del realismo castellano y valenciano. Entre los ejemplos femeninos ${ }^{5}$ destacados dentro de la escultura mediterránea está María PérezPeix, escultora que firmará con el seudónimo de Telur y Eulalia Fábregas, calificada por algunos críticos como la continuadora de José Clará.

La escultura mediterránea va a promover una simplificación y limpieza formal que supone el triunfo de la forma llena y equilibrada, del volumen y del fuerte modelado. Una escultura rústica, terrenal, donde se valora la masa, tomando el desnudo femenino como centro de investigación. Fue Maillol, quien la puso en marcha, en oposición a Rodin. “Las divergencias del siglo XX arrancan de la contraposición entre Maillol y Rodin, base de un tenso diálogo de las formas". (Hofmann 1960:35). Igualmente será decisiva la figura de Eugenio D'Ors ${ }^{6}$, que influyó en la creación del tipo de mujer mediterránea, inspiración de esa generación de escultores, entre los que se encontraba su mujer María Pérez-Peix. Su filosofía puede apreciarse en su obra, La bien plantada, donde la describe: "Veraneante en pueblo humilde, sin pintoresquismo ni rusticidad, es a la vez tan señora y tan pueblo..., es símbolo de la catalanidad trascendente". (Querol 1953: 210)

4 Como Eva Aggerholm, Carmen Jiménez, Teresa Eguíbar, Miranda d'Amico o Mª Luisa Campoy. 5 Ana Benavent y Josefina Millares fueron escultoras mediterráneas con trayectorias entrecortadas. 6 Destacado ensayista, con seudónimo Xenius, definidor del novecentismo en 1905. Fue intelectual de la zona franquista y durante tiempo Director General de Bellas Artes. Crea Los Salones de los Once y La Academia breve de crítica de Arte estableciendo un clima artístico en años difíciles.
En Castilla buscarán un realismo sobrio, que muestre la expresión emotiva, que rechace el mimetismo académico y el virtuosismo naturalista. Será de agradecer e esfuerzo de los escultores Mateo Hernández, Victorio Macho, Julio Antonio y Emiliano Barral que, a pesar de no formar un colectivo homogéneo, trabajaron por los mismos ideales, las ganas de hallar un realismo social vinculado con el pueblo. En 1931, tras proclamarse la $2^{\text {a }}$ República y publicar un manifiesto en La Tierra, se aprecia un realismo próximo al expresionismo centroeuropeo que compromete al artista con la realidad, lo obligan a comunicarse y alejarse de la belleza sin más. Estas características son apreciadas en las esculturas realizadas por Marga Gil Roësset ese año.

Contemporáneas a los anteriores destacan varias escultoras. Por su trayectoria, Eva Aggerholm será un caso particular a estudiar, ya que experimentó la aventura moderna en París a principios de siglo. Tuvo el privilegio de vivir en el centro artístico mundial del momento, consiguiendo una visión del arte más abierta, cosmopolita e impregnarse de ella. Por otro lado, la escultora Elena Sorolla, a través de su padre Joaquín Sorolla, pudo conocer y recibir influencias de los artistas más destacados del momento. También, señalar a la escultora y dibujante, Marga Gil Roësset, que se mantuvo próxima a la esfera literaria y que en su corta vida dio sobradas muestras de innovación escultórica, aunque su repentina muerte nos impide conocer cual podría haber sido su aportación.

Son pocas las mujeres que participaron en la vanguardia de nuestro país y en su mayoría pintoras ${ }^{7}$. Aún así existen dos escultoras que estuvieron impregnadas del espíritu y de los ideales vanguardistas, Marga Gil Roësset y Eva Aggerholm, ésta última expuso con los escultores de la vanguardia. La ausencia de escultoras españolas entre las figuras destacadas de la vanguardia parisiense no debe sorprender, si tenemos en cuenta el reducido número de mujeres que practicaban la escultura en España. De cualquier modo, apenas participaron escultoras de otros países siendo decisiva la contribución de la francesa Germaine Richier dentro del expresionismo.

\section{María Pérez-Peix (1879 -1972)}

Dama dela alta burguesía catalana, recibe desde su infancia y durante su adolescencia, lo que se consideraba una educación apta para una mujer de su posición. Comienza a tocar la guitarra clásica, dedicándose intensamente a su desarrollo como música. Su agilidad manual, su alto grado de sensibilidad, así como las largas horas de ensayo, dará sus frutos con rapidez. Pero su afición por la música era incompatible con la profesión de su marido, Eugenio d'Ors, con el que contrajo matrimonio en 1906. Éste necesitaba concentración y silencio para escribir, de modo que la incita a que ejercite sus

\footnotetext{
7 Recordamos los nombres de María Blanchard, Norah Borges, Maruja Mallo, Olga Sacharoff,
} Ángeles Santos, Remedios Varo y Roberta González. 
manos y vuelque su talento en una actividad artística menos ruidosa, proponiéndole la escultura como alternativa. Eugenio d'Ors, que estaba muy bien relacionado con las diferentes esferas artísticas y era amigo del escultor catalán José Clará, le pide a éste que le dé algunas lecciones a su mujer. María Pérez-Peix, nada más comenzar a modelar, se sentirá atraída por esta disciplina, destacando rápidamente por su habilidad. Tras un viaje a París en 1906 donde tiene la oportunidad de visitar el taller de Rodin y conocerlo personalmente, la joven escultora queda impresionada por el encuentro con el gran maestro. Su nieta, la escultora Esperanza d'Ors, a menudo cita las palabras que Rodin le dedicó a su abuela mientras, cogiéndole las manos, contemplaba su obra, “Mi querida española, ¿sabes lo que estoy haciendo?; estoy aprendiendo".

Como no estaba bien visto que firmara con su nombre sus obras, dada su condición social y siendo esposa de quien era, busca el seudónimo de Telur. En un recorte de prensa del diario de Barcelona, un crítico con el sobrenombre de Zenón afirma: "Aunque no nos es permitido revelar el nombre de la persona que se escuda bajo el de Telur, diremos que éste es el pseudónimo artístico de una distinguida dama barcelonesa años ha residente en Madrid. Telur nos presenta quince obras escultóricas del mayor interés." (Zenón 1935:7).

Con una fuerte personalidad y carácter, María Pérez Peix fue una mujer muy adelantada para su tiempo, llamando constantemente la atención. Se caracterizó por su forma moderna de vestir ${ }^{8}$ y entender la vida, resultando su comportamiento extravagante, para lo que se esperaba que fuera la mujer española en la primera mitad del siglo XX. A pesar de su valía artística tanto en el campo de la música como en la escultura, estuvo a la sombra de su marido. Engrosa la larga lista de mujeres, que en esos años, a pesar de tener motivos propios para ser apreciadas, fueron relegadas a un papel secundario. Su temperamento enérgico, unido a la naturaleza dominante, independiente, incluso libertina de su esposo, les llevó al divorcio en el año 1932, siendo el 1ํ de la República ${ }^{9}$. Distinguimos tres etapas en la trayectoria de esta escultora. Una primera que se inicia en 1910, cuatro años después de su matrimonio con Eugenio d'Ors y que duraría hasta 1930, dominada por el estudio de retratos. Durante este periodo la pareja vivió a caballo entre Barcelona, Madrid y París. María pudo visitar los Museos más importantes de estas ciudades, destacando los análisis de las esculturas que hizo en el Museo del Louvre. Se conservan en el seno familiar bustos realizados por la escultora de sus hijos, hermanos, e incluso algún amigo de la familia. No son representaciones miméticas donde se busque un parecido exacto con el retratado sino

8 Solía utilizar el beige y tonalidades claras para vestir, frente a los colores oscuros frecuentemente empleados por las damas de la época. Debido al luto, algunas vestían de negro toda la vida.

9 El 6 de septiembre de 1932 se dictó la primera sentencia de divorcio en España, cuya ley había sido aprobada en marzo de ese mismo año y constituyó uno de los grandes logros de la Segunda República, que además convirtió en realidad la igualdad de sexos. más bien obras idealizadas donde se persigue el arquetipo clásico de la belleza y el equilibrio de las formas. Destaca de este periodo La bien plantada $(1929)^{10}$, obra que despliega serenidad y grandeza, en la línea del clasicismo mediterráneo expandido por su maestro José Clará, del que recibió influencia.

Un segundo periodo del año 1932, fecha de su divorcio, a 1940, se caracteriza por la realización de figuras de cuerpo entero dentro de una línea más estilizada. Al igual que la mayoría de las escultoras del momento, centra su estudio en la figura femenina, bien desnuda o provista de ropa, pero a diferencia de otras artistas que hacen uso de las prendas típicamente costumbristas ${ }^{11}$, crea una colección de obras que portan la ropa más novedosa de los diferentes periodos representados ${ }^{12}$. Destaca la serie De la moda (1935), compuesta por ocho figuras de barro policromado, de las que fundió en bronce una tirada, en la actualidad dispersas por diferentes colecciones privadas. Su nieta, la también escultora Esperanza d'Ors, conserva los folletos de varias exposiciones ${ }^{13}$ individuales realizadas en estos años. Pero quizás, de todas las obras de esta década, La argentina (1932) es en la que pueda verse de manera más clara el dominio que tenía modelando. Simplifica las formas, reduciendo los volantes del vestido de la bailaora, a un juego de ondulaciones, y los flecos del mantón, a una leve textura rayada con la punta del palillo sobre la superficie. Una figura llena de gracia y donaire, de la que elimina cualquier elemento decorativo centrando la atención sobre la expresión del rostro de la mujer representada y sobre el movimiento de su pose folklórica.

Su último periodo, que se inicia con su Maternidad I (1941), se caracteriza por una serie de composiciones donde retorna a formas más volumétricas y envolventes, que nos recuerdan las creaciones más naturalistas de Maillol. Conjuntos escultóricos llenos de espontaneidad y ternura que representan escenas extraídas de su universo circundante. Representa momentos muy íntimos, como el abrazo en el que se funden una madre y su hijo, capaces de conmover al espectador y hacerle surgir toda una serie de sentimientos.

10 Este viene a ser el título de una obra escrita por su marido Eugenio d'Ors, donde presenta el ideal de mujer mediterránea. No cabe duda que María Pérez Peix quiso hacer, siguiendo un criterio personal una interpretación plástica tridimensional de la misma.

11 Varias décadas más tarde Remigia Caubet viste a sus personajes con las ropas típicas de la clase campesina de Palma de Mallorca. Un ejemplo sería el monumento titulado Als poblers que varen fe ses marjals, un homenaje a la generación de payeses de Sa Pobla de los años 20.

12 Sus continuos viajes entre Madrid, Barcelona y París hicieron que estuviera al día de las tendencias en moda y recopilar diseños de maniquíes de décadas anteriores, que luego aplicaría para realizar ese homenaje a la historia del vestir femenino.

13 Entre las exposiciones que realizó se tiene constancia documental de la celebrada en Barcelona, en 1933, en Las Galerías Layetanas y de la efectuada en Madrid, en 1935, en el Liceum Club. 
María Pérez-Peix, muere en 1972, tras haber llevado adelante una vida llena de vivencias, aunque a costa de grandes sacrificios. Destacar su coraje, su persistencia y su ilusión por enriquecerse aprendiendo continuamente nuevas cosas. Fue muy inquieta y su afán por conocer la desvió en cierto modo de una práctica continua dentro de la disciplina escultórica, aspecto bastante común entre las mujeres que en estas primeras décadas del siglo XX se adentraron en alguna actividad artística. Su aportación e interés es más sociológico que artístico, ya que aunque puede apreciarse la calidad de su obra, lo que realmente resulta novedoso es que practicara la escultura en su época, que firmara sus obras y las expusiera públicamente. Tras su divorcio, quizás por resentimiento, disminuyó su dedicación plena a la escultura y retomó su afición por tocar la guitarra. En cierta medida se inició en la escultura por su marido y la asociaba a Eugenio hasta tal punto, que puede que a ella nunca se le hubiera ocurrido practicarla por decisión propia, a pesar de la maestría que demostró. Su obra, realizada sin pretensión mercantilista, no cambió el rumbo de nuestra escultura, aunque sí el de nuestra historia, ya que con su trabajo contribuyó a abrir un camino lleno de expectativas a las generaciones de mujeres que se incorporaron al mundo del arte con posterioridad. Prueba de ello es la herencia que ha volcado en su nieta Esperanza d'Ors, hoy en día una de las artistas más destacada dentro del panorama escultórico español.

\section{Eulália Fábregas de Jacas (1901 -1992)}

Escultora influenciada por su origen y su entorno cultural, contribuye a la renovación de la corriente mediterránea al aportar una impronta personal a la ya conocida rotundidad de los volúmenes. Perteneciente a la nobleza catalana, pasa toda su infancia y juventud, en su ciudad natal, Barcelona, donde recibirá una educación apta para una señorita de su posición. En 1939 traslada su hogar a Esplugas, a la finca Can'Hospital, hasta entonces residencia familiar de verano.

En 1924 contrae matrimonio con Ramón de Sentmenat, miembro de la alta aristocracia española, con el que tendrá dos hijos. La muerte inesperada de su hijo Ramón desencadena su afición y devoción por la escultura. Si bien en un primer momento encontró refugio escribiendo dos libros de poemas, En tu silencio y Lejano $A z u l$, publicados en 1965, el recuerdo y dolor la impulsan a hacer una escultura en su memoria. Sin conocimientos técnicos se puso a modelar un Cristo espirante en brazos de la Virgen, como metáfora de su sentimiento de pérdida. “Mientras iba haciendo las figuras ella misma se admiraba de cómo aquello tomaba forma" (Lloret 1985:14). Al día siguiente las figuras se habían deformado al no tener una estructura que soportara el peso. En ese instante decide ser escultora, comenzando su trayectoria autodidacta con algún consejo.
Después de mucho esfuerzo culminó el conjunto escultórico Piedad en recuerdo de su hijo ${ }^{14}$. El resultado le hizo valorar sus aptitudes y vio que en la escultura, tenía una vía para expresarse y comunicar al mundo lo que sentía. Decide dedicarse con exclusividad a la escultura a lo largo de su vida y su siguiente paso fue tallar en piedra y madera esculturas de grandes dimensiones. Esculpió durante décadas y no expuso por primera vez, hasta 1964, en la Sala Parés de Barcelona. El éxito de la muestra, que se refleja en los elogios de la crítica, unido a la satisfacción personal, le llevó a mostrar su obra, en pocas pero importantes exposiciones individuales ${ }^{15}$. Resulta ilustrativo el asombro de la crítica por contar con una mujer entre los creadores plásticos españoles. "Es una sorpresa la aparición en un medio social elevado, de una gran escultora que se enfrenta varonilmente con el bronce y con el mármol. (...) Las artes plásticas requieren, para alcanzar su perfección, una entrega total, una dedicación absoluta que difícilmente es posible en la mujer". (Lozoya 1974:1)

La ausencia, salvo excepciones, de nombres femeninos dedicados a la escultura hace que los críticos e historiadores, cuando aparece una, en vez de centrarse en valorar su obra, como hacen con la de sus contemporáneos, se recreen en su biografía, para justificar su creación. Al Marqués de Lozoya le resulta difícil aceptar la producción de Eulalia, calificándola como "milagro" y la atribuye a la pérdida de su hijo. "El dolor fue la necesidad de entregarse al arte totalmente, con entera dedicación, como se entregan los artistas de la bohemia miserable, que ven en el Arte la única estrella que ilumine sus vidas; su única esperanza" (Lozoya 1974:2).

A pesar del rigor y serenidad de sus esculturas, éstas no resultan frías, están impregnadas de calor, ya que la escultora busca la naturalidad del gesto, la postura delicada y armónica. Son desnudos de una calidad, equilibrio formal y elegancia exquisita. "Las esculturas de Eulalia son de una belleza de la cual podríamos decir que entra dentro del clasicismo, huyendo, sin embargo, de sus rígidas normas para presentarse entonces limpia de defectos y deformaciones. Y como no aspira ser una reproducción fiel de la realidad, se ciñe a una concepción humana ideal, en la cual se presenta una gran espiritualidad". (Lloret 1985:15)

Obras de grandes formatos, esculpidas en piedra, con volúmenes rotundos, contornos redondos y formas suaves. Como escultora mediterránea coincide con sus compañeros en la elección del desnudo femenino y la maternidad, tanto en obra exenta como relieve, así como en la elección de los títulos: Reposo, mujer sentada, la serenidad, el baño, mediterránea..., aunque a menudo difiere en las poses y en la expresión de los

14 Esta escultura puede visitarse en el panteón familiar del cementerio de Esplugas de Llobregat. 15 En 1971 expone en el Centro Cultural L'Avenc d'Esplugues. En 1972 en el Castillo de la Magdalena de Sant Antoni de Calonge. En 1974 es invitada por la Dirección General de Bellas Artes a exponer en la Biblioteca Nacional de Madrid y en 1984 en el Salón de la Naciones de París, en el Centro Internacional de Arte Contemporáneo. 
rostros, de los que emana calma y armonía. Una crítica de su exposición en las Salas de la Dirección General de Bellas Artes en Madrid, lo confirma: “El público, escasamente habituado a la escultura, se sorprende gozosamente al encontrarse dentro del mundo de grandiosidad y belleza significado por las estatuas de Eulalia Fábregas. Asombra que esta tarea poderosa, ciclópea, haya sido realizada por una mujer. Sin duda alguna es ejemplo extraño entre nosotros". (Trenas 1974: 49)

Comentario que pone de relieve la escasez de muestras de escultura, en nuestro país, en ese momento, y la falta de preparación del público en este campo, a lo que añadir, la casi ausencia de escultoras. Por tanto, no es de extrañar el desconcierto de la crítica ante la obra de Eulalia, aunque es no debemos olvidar, la existencia de otros comentarios en los que la crítica pone énfasis en la fisonomía de la artista "Joven, grácil, gentilísima, con una bella prestancia... Roësset une a la pimpante gracia de su belleza, la gracia reflexiva, serena, madura de su arte". (Marquina 1927: 4) Eulalia Fábregas usa materiales tradicionales, considerados nobles, siendo el mármol el más característico. También trabaja la madera sin policromar y funde en bronce las piezas de mayor dinamismo y libertad formal. Esculturas hechas para espacios interiores y exteriores, contando con numerosa obra pública ${ }^{16}$ que puede admirarse en pueblos y ciudades de Cataluña y fuera de la región. Galardonada ${ }^{17}$ con distinciones importantes en su localidad también ha sido promotora de arte en Esplugas, propiciando los estudios de algunos artistas, como Wistremund Artero y ha donando algunos modelos en yeso a la Escuela Municipal de Arte.

La trayectoria de Eulalia Fábregas es un ejemplo de coraje, de valentía, de dedicación y superación, en un campo, como la escultura, dirigido y ocupado principalmente por hombres. Su obra es un alarde de maestría y dominio técnico, a lo que hay que añadir su aportación personal, que la distingue de otros tantos que también practicaron la escultura mediterránea y que la sitúa como figura a destacar dentro de esta corriente.

\section{Eva Aggerholm (1882 -1959)}

Nace en Dinamarca en el seno de una familia acomodada, ventaja que le permitirá recibir una excelente formación y viajar. Estudia en la Escuela de Bellas Artes de Copenhague y en 1908, se traslada a París donde acude a la Academia Humbert y al estudio de Bourdelle, donde recibe lecciones del escultor heredero de Rodin. Allí

16 La talla del Cristo yacente de la Parroquia de Santa Magdalena, el Monumento a las víctimas de la Guerra de la Plaza de las Moreres, el Alba en la plaza de Santa Magdalena, la Maternidad del Pac de Can Vidalet, San Jordi en el Palau de la Generalitat, Figura femenina en el Parque de Cervantes, otras en el Palau Albéniz, una coronando una fuente y dos más a la entrada del Palau de Pedralbes, otra en el Hotel Princesa Sofía, muchas a lo largo de la Costa Brava, en el Ministerio de Defensa de Madrid, en el Pardo, en Túnez, ...

17 En 1968 el Ayuntamiento de Barcelona le concede la Medalla de Plata de la ciudad. En 1978 el Ayuntamiento de Espulgas le da la Bandeja Honorífica y en 1983 la Medalla de Oro de la Ciudad.

$$
\text { Revista Internacional de Culturas y Literaturas, abril } 2012
$$

conocerá al pintor español Daniel Vásquez Díaz, con el que se casa en 1910, tras convertirse al catolicismo, obteniendo la nacionalidad española. Ambos viajarán por Europa y trabajarán juntos, influenciándose mutuamente. Hasta 1918, año en que se instalan en Madrid, mantuvieron su residencia en París, donde Daniel trabajó en varios proyectos con Bourdelle ${ }^{18}$. Paralelamente la obra de Eva, recibió influencia del escultor Auguste Rodin y se enriqueció del contacto con diferentes artistas de la vanguardia asentados en la capital francesa. Así mismo, existe una relación estética entre la obra escultórica de Eva Aggerholm, creadora rotunda y al mismo tiempo poética y la dimensión escultórica de los retratos de figura entera de su marido. "Esos perfiles recios, casi de bloque pétreo que se advierte en los grandes retratos de Vázquez Díaz y en la estructura lineal de sus paisajes, en los que late sin duda el mensaje escultórico de la compañera de su vida". (Benito 2000: 14)

Resulta poco usual encontrar un comentario como este, en el que se haga referencia a la influencia que se percibe entre la creación plástica de dos artistas y no sea la mujer la beneficiaria de la maestría de su compañero. Es frecuente encontrar escultoras emparentadas con artistas masculinos, obteniendo la gracia de aumentar los contactos públicos y participar en exposiciones colectivas, cosa impensable de otro modo. El precio a pagar, en la mayoría de los casos, es una vida a la sombra de ese artista, marido o padre, que le impide desarrollarse plenamente, puesto que siempre que se comenta su obra será en relación a la del otro. A veces incluso reciben tal presión externa, que se adentran en campos creativos diferentes. "La decisión de la escultora de abandonar la pintura es un reconocimiento implícito de la radical condición de pintor de su marido, que poco antes de su matrimonio, en 1910, celebró su primera exposición monográfica importante...". (Benito 1971: 82) Si bien Eva Aggerholm comienza practicando la pintura y el dibujo, pronto decide dedicarse plenamente a la escultura, donde destacó con su particular visión de las formas, que en perspectiva resultan de una modernidad extrema. La escultora huye de la representación mimética y estudia los rasgos físicos de la persona retratada aportando datos interpretados de modo personal que muestran su individualidad. En el retrato a su único hijo Rafaelito (1916), apreciamos la simplificación formal y a pesar de faltar los detalles característicos del realismo previo, todo queda dicho. Basta con observar el cabello, reducido a la mínima expresión, para conocer, a simple vista, su forma, tacto y caída.

La escultura de Eva Aggerholm participa de las características del realismo castellano. Busca un estudio de la gente y de la raza, utilizando el retrato para identificar los rasgos propios de un pueblo. En Señora Duarte (1942) muestra un rostro femenino del momento, rudo, con rasgos fuertes de gran expresión. Elimina cualquier detalle que pueda distraer, como la representación de las orejas; del cabello no incorpora los

18 Entre ellos se encuentran unos frescos para el Teatro de los Campos Elíseos. 
rizos, solo el volumen total, insinuándose su carácter ondulado por el tratamiento del material.

Resulta de interés citar las exposiciones que la Sociedad de Artistas Ibéricos organiza en Berlín y en Copenhague, presentando como escultores ibéricos a Eva Aggerholm, Manolo Hugué, Pablo Gargallo y Alberto Sánchez. La presencia de Eva Aggerholm entre los escultores de renombre antes citados, nos avala su calidad y su espíritu emprendedor cercano en ideas y acciones a los mismos. La escultora también participa en la exposición L'Art Espagnol Contemporain, celebrada en París en 1936, recibiendo el siguiente comentario: “La muestra escultórica fue bastante nutrida, con un total de veintitrés artistas y de entre ellos, muy alta la participación de aquellos que hemos ido considerando como factores de nuestra vanguardia: Eva Aggerholm, Gargallo, Mateo Hernández, Julio y Roberta González, Hugué y Pérez Mateo". (Brihuega 1985: 210)

Es un hecho que el espíritu vanguardista tiene la voluntad de experimentación, de entrega a la investigación en busca de un lenguaje más rico y menos superficial que el académico de mimesis. Hay una intención de superar la superficie de las cosas y revelarnos la verdad interna, aumentando nuestro conocimiento y desarrollando nuestros sentidos. Llegados a este punto, tanto la obra de Eva Aggerholm, como la de Marga Gil Roësset, estarían impregnadas del espíritu de vanguardia.

La iconografía femenina y el retrato dominan la producción de Eva. Apuesta por el modelado en barro para luego fundir las piezas en bronce, aunque también realiza algunas tallas en madera. Parte de su obra está en la colección del Museo Reina Sofía de Madrid, destacando Cabeza de muchacha (1948). Los rasgos físicos de la chica, resueltos con sencillez y sin apenas detalles, muestran lo necesario para transmitir su carácter. Una pieza bella, con un alto grado de simplificación, con características próximas al cubismo y a la obra de Picasso de este periodo.

Francisco Garfías recoge unas palabras muy significativas de Daniel Vázquez Díaz que hacen referencia al modo en que Eva Aggerholm y el, se enfrentaron a la creación: “Nos unió en el arte y en la vida la misma impaciencia... Los dos a nuestro modo, buscábamos el valor de la depuración expresiva; los dos queríamos que la materia quedase anulada por el concepto; que la sensibilidad venciera a la técnica, que la cera se consumiese en la llama". (Garfías 1972: 15) Por desgracia, la escultora sufre una hemiplejía del lado izquierdo, que la mantiene totalmente retirada de la creación escultórica, al menos durante una década, hasta su muerte en 1959. A pesar de su calidad como artista y de los premios ${ }^{19}$ recibidos, hasta el momento, apenas se ha podido disfrutar de sus esculturas ya que se han expuesto pocas veces y nunca todo el trabajo que hizo. Gracias al cuidado que su nieta Laura Vásquez Díaz ha

19 Recibe en 1929 el Diploma de Primera Clase en la Exposición Nacional de Bellas Artes y en 1942 es premiada con la Tercera Medalla por Retrato de la señora Duarte. ejercido sobre las obras de la escultora, muchas reproducidas en escayola, hoy en día se conserva íntegramente su producción ${ }^{20}$. Aunque su figura no cambió el transcurrir de la escultura en nuestro país, sí supuso una excepción, al ser la única escultora que tuvo la oportunidad de exponer con los artistas de la vanguardia española.

\section{Helena Sorolla (1895 -1975)}

Escultora de apellido destacado cuya obra apenas se conoce. Nace en Valencia aunque reside en Madrid durante su infancia, adolescencia y buena parte de su madurez. Conoció a José Capuz (1884-1964), escultor valenciano contemporáneo a ella, en sus estancias estivales en Valencia. De éste recibirá clases a partir de 1916, fecha en la que el escultor se instala en Madrid. En los dos años previos es importante la orientación y tutela que recibió de Mariano Benlliure, gran amigo de su padre, que a menudo frecuentaba el estudio del pintor Joaquín Sorolla. Helena realiza sus primeras esculturas en 1914 en el estudio en el que trabajaban los discípulos de su padre, pero durante dos años, no firmó ni fechó ninguna a excepción de Sevillana Bailando (1915).

Un hecho curioso que se repite en algunas escultoras de este periodo es que no firman sus obras ni ponen la fecha de realización. Esta cuestión dificulta la labor investigadora que se suple en ocasiones, aunque con cierto margen de error, catalogando las obras en función de las fechas en las que han sido expuestas. A pesar del talento que demuestran, no se plantean su actividad artística como un trabajo profesional remunerado y no sienten la necesidad de catalogarlo. Educada al igual que sus hermanos, bajo la tutela de su madre y las ausencias de su padre, que viajaba constantemente, Helena Sorolla crece en un ambiente de autonomía y libertad. Asistió al Instituto de libre enseñanza, donde las clases eran mixtas, frente a los colegios de monjas donde acudían las señoritas como ella. Eran clases dinámicas, donde nada se imponía y todo se razonaba. A veces se desarrollaban en el jardín, otras iban a la Sierra a esquiar. Una manera muy libre de vivir, más que la de cualquier otra familia del momento ${ }^{21} \mathrm{y}$ un entorno artístico que la influyó toda su vida, le hizo tener ilusión por conocer, inquietud por observar y aprender. Tuvo la oportunidad de conocer a Rodin en un viaje a París, quedando impresionada con su obra. Anécdota que comparte con María Pérez-Péix y Eva Aggerholm, que también visitaron el estudio del maestro. Su trayectoria como escultora estuvo entrecortada por los acontecimientos que dirigieron su vida. Se casa en 1922 con un ingeniero de montes, recorriendo diversas ciudades antes de asentar su residencia en Madrid. Fue madre de siete hijos y aunque contó con servicio que le ayudaron en el cuidado de los mismos, este hecho hizo que disminuyera su dedicación a la escultura. La Guerra Civil, la obligó a marchar a Portugal, Francia y San Sebastián,

20 Está a la espera de que se produzca la catalogación de toda su obra y una muestra antológica.

21 Helena hace la comunión a los 22 años, cosa impensable en una señorita de aquella época. 
volviendo a Madrid en 1939. En 1964 muere su marido y dos años más tarde realizó su última escultura, un Autorretrato (1966) de gran calidad. A partir de entonces, atenta a los acontecimientos culturales, frecuenta el teatro y asiste a numerosas exposiciones. Como escultora participó sólo en tres muestras, en la Exposición de Arte Joven Valenciano en 1917, en la Exposición de Arte de Barcelona en 1922 y en una exposición con su hermana María en el Club Femenino Español de Madrid en 1926.

Muchas de sus obras son retratos, estudios de personajes en yeso policromado como Cabeza de mujer (1916). Éste es un material muy delicado, que necesita unas condiciones óptimas para su buena conservación. No es de extrañar que algunas de sus esculturas se hayan estropeado o roto, encontrándose en paradero desconocido, y que en el Museo Sorolla sólo se muestren algunas de las que están en mejor estado. También existen retratos que hizo a sus hijos y familiares, entre 1924 y 1934, que se conservan en las residencias de los mismos.

Helena utiliza el bronce como material definitivo en obras de pequeño formato. En ellas representa figuras femeninas de cuerpo entero en actitud serena, con poses académicas, que desprenden refinamiento y clasicismo. En el Museo Sorolla se conservan un par de ellas de mayores dimensiones, Desnudo de mujer (1926) y Mujer sentada (1926), aunque no alcanzan el tamaño de una persona al natural. A diferencia de Eva Aggerholm entre los objetivos de Helena Sorolla no estaba la búsqueda de nuevos caminos para la escultura. Puede decirse que su obra sin ser propiamente novecentista, ya que elimina el artificio y los datos anecdóticos, se basa en un estudio del natural siendo pocas las obras en las que se aleja del modelo para realizar una aportación o interpretación personal. Es una escultura de buena calidad técnica y gran belleza, que la artista desarrolló para disfrute personal. Si bien es cierto que la escasa producción de la artista, nos impide hacer un juicio de lo que pudo haber sido su aportación a la escultura, lo que sí está claro es que su importancia reside en el hecho de haber sido escultora en su momento. Es una fortuna el hecho de que Helena sea hija del famoso pintor y que exista un museo dedicado a exponer la pintura de Joaquín Sorolla ${ }^{22}$, puesto que parte de sus esculturas se conservan en el. De lo contrario, probablemente no tendríamos constancia de su vocación escultórica o en el mejor de los casos desconoceríamos el paradero de sus creaciones.

\section{Marga Gil Roësset (1908 -1932)}

22 El Museo se crea en el año 1931 al aceptar el Estado español el legado de la viuda del pintor. Es un ejemplo de una casa de artista de principios del siglo XX.
De familia acomodada ${ }^{23}$ con inquietudes artísticas y culturales, contó con varias mujeres, entre sus familiares, dedicadas a la creación pictórica ${ }^{24}$. La escultora nace en Madrid y desde pequeña, recibió una educación integral, estimulada por su madre. Su hermana Consuelo y ella asistieron al Colegio de las Madres Irlandesas ${ }^{25}$ de Madrid, para cursar estudios oficiales, pero tras comprobar que la formación que ellas tenían era superior a la que impartían las mojas, abandonaron las clases y continuaron su instrucción bajo la tutela de su madre. Hablaban cuatro idiomas, asistían a conciertos, a menudo viajaban por Europa, Consuelo escribía y Marga dibujaba.

A los siete años Marga escribió e ilustró La niña curiosa y continuó realizando las ilustraciones de los libros escritos por su hermana Consuelo ${ }^{26}$. Aprendió a dibujar en el estudio del pintor López-Mezquita, realizando en su corta vida cerca de un centenar de dibujos. A los catorce años, se interesó por la escultura y empezó a modelar. Su madre la llevó al estudio de Victorio Macho quién al ver sus trabajos dijo, “deje usted a su hija que siga sola" (Arciniega 1930: 23), de modo que inició una carrera autodidacta. Fue una artista moderna, que a pesar de su juventud demostró gran talento. Los críticos del momento no supieron encontrar parecido o influencia alguna, de modo que sus esculturas resultan de una gran originalidad, distintas, únicas.

A pesar de ser una chica llena de energía, resulta poco corriente la cantidad de obras que hizo en tan poco tiempo, lo que implica que tuvo que dedicar muchas horas diarias a su trabajo. Era una joven introvertida, observadora, que cada día se encerraba en su taller modelando formas y dibujando fantasías, con un sentido armónico y sarcástico a la vez, que provenía de su rebeldía contra lo bello y su amor hacia la expresividad de las taras fisiológicas. Sin contar las que destruyó antes de morir, ya que desconocemos su número y no existen fotografías, se conservan dieciséis esculturas, cuatro realizadas en piedra y el resto algunas en escayola y otras en madera.

Las esculturas que Marga hizo en torno a los quince años, justo cuando acababa de empezar a esculpir, son de dimensiones que oscilan entre los veinte y sesenta centímetros. La mayoría fueron realizadas en escayola y patinadas con betún de Judea y dorado. Representan niños, muchos en posturas y semblantes caricaturescos, de gran expresividad, como Niños abrazados (1923). "Eran bastantes ingenuas en cuanto a temas, pero de un dominio técnico asombroso. Algunas recordaban a los dibujos de

23 Descendiente por rama materna de gallegos ilustres y por la paterna de un ingeniero francés que vino a España a mitad del S. XIX a realizar las instalaciones ferroviarias de Portugal a España.

24 María Roësset, hermana de la madre y su prima Marisa Roësset.

25 Colegio con una formación, basada en valores cristianos, que incluía clases de costura y misa diaria. Les enseñaban cómo ser esposas ejemplares y comportarse en sociedad. Acudían las hijas de las mejores familias, como Doña María de las Mercedes de Borbón y Orleáns, madre del Rey.

26 El niño de oro, publicado en 1920, Rose des Bois, publicado en París en 1923, Canciones de niños, publicado justo después de su muerte, en 1933.

$185-3625-100$


Ferrándiz; todas eran manifiestamente orientales". (Serrano 2000:16) Se trata de una obra irónica donde la artista no pretende una copia mimética de la realidad, sino realizar una intervención personal, desnudando la obra de dentro a fuera. Para ella son más importantes las ideas que la parte física del personaje, de ahí que logre transmitir tanta emoción. Sus personajes, a menudo carentes de belleza física, consiguen atraernos por su simpatía y sus gestos traviesos. “Piensa y siente primero lo que ha de crear; después selecciona los ejemplos vivos; por último, ejecuta despiadadamente consigo misma y con el modelo. Esa falta de piedad, de compasión enfermiza, pero no de ternura, es lo que caracteriza a Marga" (Francés 2000:42). Un ejemplo de su concepción estética y su manera de entender la vida sería su obra Para toda la vida(1930). En ella contrasta la ternura de la composición, en la que aparecen dos niños abrazados, con la forma en que representa esa unión, les junta los pies con un grillete. Hace un guiño irónico y representa el matrimonio como estar encadenado. Es ilustrativo el comentario de Marga: “No creo en el amor simultáneo de dos corazones... Yo puedo enamorarme de un hombre sencillamente porque me gusta; pero me parece difícil que él al mismo tiempo se enamore de mí, completando así el amor. Me parece que en esto hay siempre un sacrificado". (Arciniega 1930: 23)

En 1930, con veintidós años, presentó su obra Adán y Eva a la Exposición Nacional, recibiendo muy buenas críticas. El conocimiento que la artista tenía de la anatomía humana queda patente en esta obra, que además destaca por la fuerza expresiva de sus personajes, sometidos a un alto grado de estilización. La escultora describe lo que quiso expresar en la obra:

\section{Adán y Eva, padres del género humano. Viejos como el mundo. Atlético él, fuerte como para engendrar a todos los hombres. Débil ella, apoyada en el robusto pecho del hombre, pero amplio su seno como para amamantar a toda la Humanidad. En sus caras he rero amplojo su seno conó para anamantar a toda la Humanidad. En sus caras he reflejado el dolor del paraiso perdido, dolor de sentirse solos en medio del planeta, dolor por todos los dolores que habrán de arrastrar sus hijos a través
de los siglos. (Arciniega 1930: 23)}

Sus palabras desprenden un hondo sentir, que hace de su obra una metáfora de su propio dolor, el que se desprende al vivir todo con tanta pasión y entrega, dejándole un sabor amargo en la boca, un estado continuo de melancolía provocada por la incomprensión y la soledad que sufre. José Francés, describió nítidamente su semblante, "Conservaba frente al mundo y las gentes un aire de alejamiento espiritual, de precoz hastío característico e inadecuado a sus años infantiles". Un par de años después, a principio de 1932, conoció a Juan Ramón Jiménez y se ofreció a hacer un busto de Zenobia, su esposa y otro de él, aunque este último nunca lo realizó. A partir de ahí, Marga quedó prendada por la figura de Juan Ramón, no pudiendo resistir el galanteo que éste ejercía sobre ella. Se enamoró del poeta, casado y mucho mayor que ella, que dada su posición social y familiar no podía corresponderle. La escultora frustrada ante la imposibilidad de vivir su pasión, se hundió emocionalmente. Destruyo parte de sus esculturas y terminó con su vida, de forma trágica a los 24 años de edad, tras pegarse un tiro. De aquí que a menudo la comparen con la escultora francesa Camille Claudell, que sufrió el despecho del maestro Auguste Rodin, lo que le llevó a destruir parte de su obra y terminar internada en un psiquiátrico hasta su muerte.

A pesar de su juventud, Marga Gil Roësset, había despertado la curiosidad por su obra de algunos críticos. Su nivel cultural le permitió relacionarse y mantener una buena amistad con personajes ilustres del mundo de las letras, muchos de los cuales le dedicaron algunos poemas tras su muerte. En especial, Juan Ramón Jiménez, con quien tuvo una relación estrecha y personal. “Tu sufrimiento, muerta tú, se ha quedado expandido sobre mí, como el rojo del sol, después de puesto, por la tarde. Sentimiento sordo, profundo, concentrado, inmenso, como el rojo de la puesta de sol en un crepúsculo eterno. Agosto 1932". (Jiménez 2000: 23)

Inmersa en las corrientes estéticas de principio de siglo, puede apreciarse en su obra el efecto del modernismo así como la influencia del arte oriental. “Escultora enérgica, vibrante y misteriosa,..., deja irse las horas en la calma fecunda, solitaria, de su taller de escultura... De ahora en adelante cuando se hable de la escultura española, hay que citar el nombre de Marga y el arte de Marga... Se está, pues, en presencia de un artista verdadero que no le debe nada a profesores ni maestros". (Francés 1929: 17) Su última escultura, La mujer del ahorcado (1932), una talla directa en piedra, refleja el tormento ante la pérdida de un ser querido. Trasmite el dolor y la fuerza desgarradora que desprende el momento. Al interés del contenido, hay que añadir el dominio técnico, en el uso del puntero y la gradina, así como la calidad de la composición, donde la tensión del cuerpo de la mujer arqueado hacia atrás es compensada por su hijo, de rodillas a sus pies.

Marga Gil Roësset fue una escultora de mirada enigmática y profunda, que vivió deprisa una vida corta pero intensa, llena de talento y romántica pasión que podría ilustrar cualquier libro de la bohemia y la vanguardia de principios de siglo. Su historia narrada en diversas ocasiones con el interés puesto en su biografía ${ }^{27}$, se muestra por primera vez centrada en su obra en el año 2000, en una exposición antológica en el Círculo de Bellas Artes de Madrid. Su ansia por comprender, por experimentar, por poseer lo que quería, la condujo a su autodestrucción. Logró trasmitir fuertes sensaciones que aún hoy nos conmueven e inquietan al contemplar sus dibujos y esculturas. Comenzó creando rostros entrañables de los que emanaba ternura, para concluir su trayectoria haciendo volumen sus pesadillas, esculpiendo sus pensamientos más tortuosos. Su

27 En Febrero de 1997 el ABC Cultural narra su historia y también Joaquín Leguina publicó, Malvadas y virtuosas. Retratos de mujeres inquietantes, entre las que se encontraba Marga. 
trágico destino nos impide disfrutar de lo que podría haber creado en el transcurso de una vida natural.

\section{REFERENCIAS BIBLIOGRÁFICAS}

Alix, J. y Brihuega, J., Escultura española 1900/1936, Madrid, Dirección General de Bellas Artes y Archivos, Ministerio de Cultura, 1985, pp. 29 - 210.

Arciniega de Granda, R., "Las mujeres en la exposición Nacional de Bellas Artes”, Revista Crónica, Madrid, 23 de Junio (1930), p. 23.

Barrionuevo Pérez, R., Reexistencias. Escultoras españolas del siglo XX, Madrid, Comunidad de Madrid, 2006.

Benito, Á., Daniel Vázquez Díaz y Eva Aggerholm en las colecciones del Reina Sofía de Madrid, Nerva, Diputación de Huelva y Fundación Vázquez Díaz, 2000, p. 14.

----, Vázquez Díaz: Vida y pintura, Madrid, Dirección General de Bellas Artes, Ministerio de Educación y Ciencia, 1971, p. 82.

Berasategui, B., "Historia de Marga”, ABC Cultural, Madrid, 7 de febrero (1997), pp. 16 - 23. Bonet, Juan Manuel, Diccionario de las Vanguardias en España (1907-1936), Madrid, Alianza Editorial, 1995, p. 456.

Clark, M., Amarga luz, Madrid, Ed. Funambulista, 2011.

De Castro Arines, J., Escultura figurativa 1900/1950, Santander, Fundación Marcelino Botín, 1987, pp. 5-7.

Francés, J., “Marga Gil Roësset”, La Esfera, Madrid, 17 de agosto (1929), p. 17.

----, “Responso a Marga Gil Roësset”, Nuevo Mundo, Madrid, no 2008, (1932).

Garfías, F., Vida y obra de Daniel Vázquez Díaz, Madrid, Ibérico Europea de Ediciones, S.A., Col. Arte Contemporáneo Español, 1972, p. 15.

Hofmann, Werner, La escultura del siglo XX, Barcelona, Seix Barral, 1960, p. 35.

Huici, Fernando y De Diego, Estrella, Fuera de Orden. Mujeres de la Vanguardia Española, Madrid, Fundación Cultural MAPFRE VIDA, 1999.

Jiménez, J. R., “Lo de Marga”, Marga Gil Roësset (1908-1932), Madrid, Círculo de Bellas Artes, 2000, p. 23.

Lafuente Ferrari, E. y Camon Aznar, J., Un siglo de arte español: 1856-1956, Madrid, Dirección General de Bellas Artes, 1955

Lloret, Pascual J., 4 Medalles d'Ors: Angelina Alós i Tormo, Xavier Corberó Olivella, Eulalia Fábregas i Jacas,

Pere Mañé i Baleta, Barcelona, Col.lecció Documents 1, Ajuntament d’Esplugues, 1985, pp. 13-15.
Lozoya, Marqués de, Eulalia Fábregas Sentmenat, Madrid, Ministerio de Educación y Ciencia, Dirección General de Bellas Artes, Comisaría General de Exposiciones, 1974, pp. 1-2.

Marín Medina, J., La escultura española contemporánea (1800-1978): Historia y evaluación crítica, Madrid, Biblioteca de artes contemporáneas 1, Edarcón, 1978, p. 159.

Marquina, Rafael, “En el Lyceum Club. Exposición Marisa Roësset”, El Heraldo de Madrid, 10 de Enero (1927), p. 4.

Pérez Reyes, C., La escultura del siglo XX, Madrid, Ed. Historia 16, Cuadernos de Arte Español, № 80,1992, p. 10.

Querol Gavalda, M., La Escuela estética catalana contemporánea, Madrid, Consejo superior de investigaciones científicas, C.S.I.C., 1953, p. 210.

Ruiz Bremón, M., Catálogo de escultura: Museo Sorolla, Madrid, Ministerio de Cultura, 1993, p. 41.

Serrano, A., Marga Gil Roësset (1908-1932), Madrid, Círculo de Bellas Artes, 2000, pp. 14-33.

Trenas, J., “Arte y artistas en Madrid: Formas Mediterráneas en la escultura de Eulalia Fábregas Sentmenat", La Vanguardia Española, Barcelona, 3 de Mayo (1974), p. 49.

Van Der Sanden, Hermine Catry, "Situación de la mujer española en el siglo XX: Un largo camino", Revista Mosaico, 1, (1998), pp. 7-10.

Zenón, “En las Galerías Layetanas. Exposición Telur”, Diario de Barcelona, Sección Arte y Letras, Barcelona, 3 de Enero (1935), p. 7. 